\title{
Frame Distinction of the Lexical Entries and Metaphors in the Malayalam-English Dictionary
}

P. M. GIRISH

\section{Abstract}

It is a fact that the new emerging linguistic resources like Fillmore's theory of frame semantics and George Lakoff's Metaphor theory can be used in the domain of translation for accuracy and adequacy. Bilingual dictionary also comes under this notion since it gives translation of entry words and usages from one language to another. This paper examines the nature of semantic differences between words and their apparent translation equivalents in the Malayalam - English Dictionary (Published by D. C. Books Kottayam), with special reference to metaphor, from a cognitive linguistic perspective. Bilingual dictionary may also be considered as a tool for translators since it expresses cultural sense. This paper argues that adequate knowledge in cognitive linguistics helps translators and lexicographers for better performance.

Keywords: Bilingual Dictionary, Cognitive Linguistics, Corpus, Domain, Frame, Figure-background Knowledge, Lexeme, Metaphor.

\section{Introduction}

This paper examines the nature of semantic difference between words and their apparent translation equivalents along with the metaphorical expressions in the Malayalam - English Dictionary, henceforth referred to as $\mathrm{MED}^{1}$ from a cognitive linguistic perspective. Cognitive Linguistics offers a promising approach for the analysis of meaning. It argues that language is governed by general cognitive principles, rather than by a

\footnotetext{
${ }^{1}$ The most popular bilingual dictionary in Malayalam prepared by M.I. Variar, E.V. Narayana Dhatathiri and K. Radhakirshanan and is published by D.C. Books, Kottayam in 1990.
} 
special-purpose language module. Cognitive linguists have developed several new methods to describe meaning is generally known as cognitive semantics. Frame semantics is one among them. Fillmore, the icon of cognitive semantics, describes his frame semantic model as model of the semantics of understanding, in contrast to truth - conditional semantics ${ }^{2}$.

\section{Frame Semantics}

According to Fillmore frame is "coherent region of human knowledge or as a coherent region of conceptual space (Fillmore 1992: 11). It may be any system of concepts related in such a way to understand any one of them, one has to understand the whole structures in which it fits. Frame refers to background knowledge necessary for the understanding of semantics units. Other writers have used a variety of terms to refer to frame. For John R Taylor frame is domain.

Cognitive linguist like Langacker (1989) uses more empirical approach to identify frames based on the words and contractions of a human language such as English (Croft 2004: 150). Langacker describes his approach by taking 'radius' as an example, that joins the centre of a circle (see the illustration).

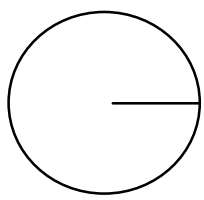

\footnotetext{
2 Truth- Conditional Semantics: It is one of the major approaches to semantics. It establishes that 'meaning' can be defined in terms of the conditions in the real world under which a sentence may be used to make a true statement. Donald Davidson (1967/1971) argues that 'We will obtain a better theory of meaning if we replace the notion of a sentence's verification condition with that of the sentence's truth condition.: The condition under which the sentences actually are or would be true, rather than a state of affairs which would merely serve as evidence of truth.
} 
The line segment is defined relative to the structure of the circle. It means that speaker can understand Radius only against a background understanding of the concept circle. They are related to each other. According to Langacker it is relatively of a concept profile against a base. "The profile refers to the concept symbolized by each word in question. The base is that knowledge or conceptual structure that is presupposed by the profiled concept" (Croft 2004: 150). Hence, the profile - frame distinction is useful in understanding the nature of semantic differences between words and their translation equivalents in different languages and metaphors as well. It is important to realize that metaphor is linked with new construction. An author can conceptualize a concept in different ways. For example: 'angry'. There are lots of metaphorical expressions to refer to anger in Malayalam: i. cuutaakuka, ii. pottiterikuka. Translators should also be aware of these kinds of expressions for better translation.

\section{The Metaphor Theory}

Metaphor represents our thinking and it makes our communication more powerful. Metaphor is much more than a "literary ornament". It means that metaphor is not a rhetoricaldevice alone. "Cognitive Linguistics rejects the so-called substitution theory of metaphor, according to which a metaphorical expression replaces some literal expressions that have the same meaning" (Croft 2004: 194).The cognitive theory of metaphor as developed by George Lakoff and Mark Johnson (1980) endows metaphor with the important cognitive function of explanation and understanding. George Lakoff and Mark Johnson (2003) summarises the key ideas about metaphor: (i) metaphors are fundamentally conceptual in nature: metaphorical language is secondary, (ii) conceptual metaphors are grounded in every day experience, (iii) abstract thought is largely, though not entirely, metaphorical, (iv) 
metaphorical thought is unavoidable, ubiquitous, and mostly unconscious, (v) abstract concepts have a literal core but are extended by metaphors, often by many mutually inconsistent metaphors, (vi) abstract concepts are not complete without metaphors. For example, love is not love without metaphors of magic, attraction, madness, union, nurturance, and so on, (vii) our conceptual systems are not consistent overall, since the metaphors used to reason about concepts may be inconsistent, (viii) we live our lives on the basis of inferences we derive via metaphor (Lakoff \& Mark Johnson 2003: 272). It shows that metaphors have a significant role to play in our life. Conceptual metaphors are basic cognitive structures by means of which one subject matter is understood in terms of a completely different domain of experience. Human beings structure their understanding of their experiences in the world through conceptual metaphors derived from fundamental concepts learned from the way of life. Environment has a pivotal role in shaping people's metaphorical expression in order to reveal their thoughts and emotions. In English, there is a considerable number of metaphorical expression in which emotions are conceptualized in terms of plants and their parts. (Example: A romance is budding, planted the seed of hatred, jealousy germinate when the mind gets corrupted, love sprouted, fear is growing, deeply rooted fear, etc). In Malayalam, the agricultural metaphors also engross the source domain and the target domain. For example: koziyuka: the literal meaning of koziyuka is fall off. When it is attached with the word palla (teeth) it gets the meaning of lost teeth and it is also extended to the metaphorical usage like: to become old/lose the vigor'.. Here are some more examples: (1) mulakkuka: the literal meaning of the word 'mulakkuka' is germination of a seed. But here, the sense of it has been metaphorically extended to the secondary meaning such as 
'appear/come'. For example: palla mulakkuka: reach the stage of childhood when teeth begin to appear and become ready to bite or attack (2) The literal meaning of the word, vaati is 'fade' or became feeble and it has always connected to flower and leaf etc. The metaphorical expression of this word is 'not having good health'. For example: nii vaati pooyi ([you] are not having good health). (3) The word, veer means: (of plant) root, means, the part of a plant which grows under the ground and absorbs water and minerals and send to the rest of the part of the plant. The metaphorical usage is 'basic'. For example: presnatinte veerukal (root of the problem).

As far as translation is concerned the metaphorical usages of the entry word are also significant in bilingual dictionary in addition to give apparent translation to the target language.

\section{Translation Process in MED}

Bilingual dictionaries are not regarded as a long list of words or linguistic expressions from source language to target language. In MED, Malayalam is the source language and English stands as the target language. Bilingual dictionaries are considered one of the translator's tools since a translator might primarily depends on them for the word's semantic sense, grammatical categories and figurative usages. The bilingual dictionary like MED has two types of translations: (i) translation of the lexical entries of the source language into the target language's lexical items (ii) translation of the metaphorical usages of the source language into the target language. If both of these translations are in a proper manner, it would be an asset to any translator.

It is argued that bilingual dictionary should focus on figure background nature of a word and its metaphor as well. A good lexicographer should have profound knowledge in semantic 
theories such as cognitive semantics. Then bilingual dictionaries would become an apt device for translators. Having described this much, the rest of the paper examines the sample data collected from the MED. It also emphasizes the significance of frame concept.

\section{Sample Data}

The sample data analysis has four steps: (i) the presentation of the lexical entries in the MED (ii) frame semantics analysis of the entry word (iii) verification of the metaphors in the MED and (iv) the sample data analysis with special reference to translation equivalents in the MED.

\section{Example: 1}

\section{Step: I}

amma/naa/: mother (Here, naa refers to noun) (1990: 72)

\section{Step: II}

For frame semantics, amma, means mother is not a 'woman who has given birth to a child', it is more than that, "Mother is a concept that is based on a complex model in which a number of individual connive models combine, forming a cluster model. The models in the cluster are: the birth model: The person who gives birth is the mother. The birth model is usually accompanied by a genetic model: The female who nurtures and raises a child is the "mother 'of that child. The nurturance model: The wife of the father is the 'mother. The genealogical model: The closest female ancestor is the mother (Lakoff 1990: 74-75).

\section{Step III}

The metaphorical usages are not even mentioned in the MED. In Malayalam, there are a lot of metaphorical usages for amma such as female goddess, religious leader, source and 
political/community leader and so on. The thought processes of a speech community are expressed through metaphors. Therefore, lexicographers should accommodate metaphors in dictionaries, as much as they could. If only, it would be a helpful resource/ translation tool for translators.

\section{Step IV}

The MED, gives only a single equivalent to amma in English. This lexical entry did not even consider the frame-the encyclopedic knowledge or background knowledge of the concept of amma. The lexicographers should have considered the socio-political background of the entry words to include the metaphorical usages. Hence, this particular lexical entry is inadequate for the translators who wish to take this dictionary as a translation tool and users as well.

Here are some more examples intended to illustrate the frame/domain notions:

\section{Example: 2}

dveep - naa : turutto $\mathrm{n}$. island (1990: 543)

\section{Step I}

For frame semantics, dveepə is an island alone.

\section{Step II}

Frame Semantic approach to this lexical entry: Dveep means an Island is a mass of land completely surrounded by water. 'The word designates the land mass, it does not designate the water. However, the notion of the surrounding water is intrinsic to the concept; if there were no surrounding water, there would be no island, While the notion of the surrounding water is in the base of the semantic unit [ISLAND], the profile-base relation itself presupposes the border domain of the Earth's geophysical features'(Taylor 2002: 198-199). 


\section{Step III}

The metaphorical usages are not even mentioned in the MED. This lexical entry has some metaphorical expressions too. The word, dveepa, can also metaphorically be used to refer to 'aloofness' and isolation etc., in Malayalam. For example: avan oru dveepo aano (He became aloof and silent).

\section{Step IV}

The lexicographers have hardly ever given metaphorical usages to some lexical entry as figurative language. For example the lexical entry - carakka.

carakk naa: saamaanam, vilppanasaamaanam, utpanam, valiya oottupaatram (vaarppə), (Jai) maadakasuntari/good, commodity, merchandise, textile goods, large cauldron, Fig. a voluptuous, attractive woman.

This might help both the translators and users/learners. Nevertheless the lexicographers are not in proper to give all the entries. They should include the metaphors also since metaphor represents our thinking and it makes our communication more powerful.

\section{Example: 3}

\section{Step I}

fani: 'navagrahnநhaliloonna, fivan, (Jai) nirantaram upadavicukkondirikkunnavan', one of the nine plants, Saturn, Saturday, Siva (fig.) one who constantly harasses another

\section{Step II}

fani, Saturday, profile, a 24 - hour period, i.e. a 'day' against the base of the seven-day week. The concept presupposes a rich network of domain-based knowledge, including: 


\section{P. M. Girish}

- The practice of designating the day-night cycle as a 'day', which is conventionally taken to begin at a point (midnight) which is mid-way between successive high points of the sun,

- The convention of grouping days, as characterized above, into a seven-unit cycle, the idea of the seven-day going back, ultimately, to the Biblical creation story;

- The convention of naming the component units of the cycle,

- The idea that different units of the cycle may be suitable for different kinds of activities, such as work, recreation, or devotion (Taylor 2002: 200).

\section{Step III}

Here, in MED, the lexicographers have given superficially the metaphorical meaning of the lexical entry too. But in Malayalam, the word fani, has a various metaphorical usages both in spoken and written forms. It is very significant in astrology and religion. Here are some: faniyan (unfortunate, unluckily), fanidesa (Bad time) kandakafani (treacherous period) and so on.

\section{Step IV}

The lexicographers should have given more metaphorical usages since metaphor carries the socio-cultural values of the speech community.

\section{Grammatical Entries and Metaphors}

So far this paper examines the lexical entries and metaphors in MED. Now it turns to grammatical categories and its metaphorical usages. MED does not consider these two categories. Since Malayalam belongs to agglutinative language- which means, words can be formed by combining stem and multiple affixes to create a large set of different 
forms for each word- the suffixes should have been considered as lexical entries. It is observed that affixes are also used metaphorically in Malayalam. For example: $-i l$ is the locative marker in Malayalam. It can also be used metaphorically.

i. avan veetfil unto (She is at home)

ii. aval manasil untz. (She is in mind) In this sentence - il is used as conventionalized metaphor in terms of location.

\section{Conclusion}

This paper tries to answer to the general question of why translation is often difficult especially in the bilingual dictionaries, by examining the Malayalam- English Dictionary. Lack of semantic knowledge of the lexicographers makes problems in making dictionaries. Profile - frame distinction is useful in understanding the nature of semantic differences. It is a solution for the 'translation- problem'. Lexicographers should keep in mind this when they prepare a lexical entry. In addition to this they must also give prominence to metaphorical usages since the metaphors reflect our ability to think of one thing in terms of something else. The MED is not an observant one. Main problems of the MED entry words do not evoke specifically a frame. Therefore semantic translations of these words are inadequate for understanding the metaphorical meanings. Besides, it would not help the translators who depend on the MED as a translation tool. Lexicographers can also use the newly introduced corpusbased techniques ${ }^{3}$ to recognize the frequency of occurrence of words and metaphorical expressions.

\footnotetext{
${ }^{3}$ Unlike manual preparation, computers can find all the instances of a word in a corpus and generate an exhaustive list of them. Corpus can be used for identifying the most common words and for providing an outline of the relative frequencies of nouns and verbs in a text.
} 
P. M. Girish

\section{References}

Chomsky, N. 1965. Aspects of Theory of Syntax. Cambridge: MIT Press.

Chomsky, N. 1959. A Review of B. F. Skinner's Verbal Behavior. Cambridge: MIT Press.

Croft, William.; and D. Alan Cruse. 2004. Cognitive Linguistics. Cambridge: Cambridge University Press.

Fairclough, Norman. 1989/1993. Language and Power.

London: Longman

FaUCONNIER, Gilles. 1995. Mental Spaces. Cambridge: Cambridge University Press.

Lakoff, George.; and Mark Johnson. 1980. Metaphors We Live By. Chicago: University of Chicago Press.

LANGACKER, R. 1990. Foundations of Cognitive Grammar Vol. X.

Stanford: Stanford University Press.

LANGACKER, R. 1987. Foundations of Cognitive Grammar Vol X. Stanford: Stanford University Press.

TALMY. 1983. 'How Language Structures Space, in Spatial Orientation: Theory, Research and Application. Pick \& L Acredolo ( ed.). New York :Plenum Press.

TAYLOR, John. R. 2002. Cognitive Grammar, Oxford: Oxford University Press.

VARIAR, P. I.; NARAYANAN NAMBOOTHIRI, E. V.; and RADHAKRISHNAN, K. (eds.). 1990 Malayalam-English Dictionary. Kottayam: D. C. Books. 